\title{
SUBSTITUIÇÃO DE COQUE POR CARVÃO VEGETAL NA SINTERIZACÇÃO E SEUS EFEITOS NA REDUÇÃO POR HIDROGÊNIO DE SÍNTER DE MINÉRIO DE FERRO *
}

\author{
Victor Bridi Telles ${ }^{1}$ \\ Jorge Alberto Soares Tenório ${ }^{2}$ \\ Denise Crocce Romano Espinosa ${ }^{3}$
}

\section{Resumo}

Este trabalho teve por objetivo estudar a redução por hidrogênio de sínteres produzidos com coque e carvão vegetal. Para isso, foram realizados 6 ensaios de sinterização substituindo o coque por carvão vegetal como combustível do processo. As substituições foram de $0 \%, 8 \%, 16 \%, 25 \%, 50 \%$ e $100 \%$. As amostras com substituições de $0 \%, 50 \%$ e $100 \%$ foram reduzidas em termobalança, durante 6 horas, em temperatura de $1000^{\circ} \mathrm{C}$, utilizando uma mistura de gases contendo Argônio - 10\% Hidrogênio. Os resultados mostraram que, para as misturas produzidas, o sínter fabricado com carvão vegetal diminuiu os índices de produção da sinterização e de resistência do sínter. Contudo, o sínter produzido utilizando somente carvão vegetal como combustível, apresentou maior redutibilidade.

Palavras-chave: Redução, hidrogênio, sinterização.

\section{REPLACEMENT OF COKE BY CHARCOAL IN THE SINTERING PROCESS: EFFECTS ON THE HYDROGEN REDUCTION OF IRON ORE SINTER \\ Abstract}

This work aimed to study the sinter reduction by hydrogen produced with charcoal and coke breeze. Six sintering tests were conducted replacing coke breeze by charcoal as process fuel. The replacements were $0 \%, 8 \%, 16 \%, 25 \%, 50 \%$ and $100 \%$. The samples with substitutions of $0 \%, 50 \%$ e $100 \%$ were reduced in thermobalance for 6 hours at a temperature of $1000^{\circ} \mathrm{C}$ using a blend of gases containing Argon - 10\% Hydrogen. The results showed the sinter made with charcoal decrease the sinter rates of production and resistance. However, the sinter made using only charcoal as fuel presented better reducibility.

Keywords: Reduction, Hydrogen, sintering process.

1 Doutor em Engenharia Química, pós doutorando no Departamento de Eng. Química da Escola Politécnica na Universidade de São Paulo.

2 Doutor em Engenharia Metalúrgica e de Materiais, Professor Titular no Departamento de Eng. Química da Escola Politécnica na Universidade de São Paulo.

3 Doutora em Engenharia Metalúrgica e de Materiais, Professora no Departamento de Eng. Química da Escola Politécnica na Universidade de São Paulo. 


\section{INTRODUÇÃO}

A utilização de combustíveis e agentes redutores na indústria metalúrgica colaboram para a geração de gases causadores do efeito estufa. Uma vez que a produção de ferro e aço é responsável por cerca de $6,7 \%$ das emissões destes gases, tem sido estudadas novas alternativas nos processos metalúrgicos e nas matérias primas para a produção de ferro. [1]

A sinterização de minérios de ferro consiste em parte do problema. Plantas de sinterização emitem $18 \%$ dos gases poluentes gerados na indústria e utilizam coque como combustível. De acordo com alguns autores, no processo de sinterização são gerados $216 \mathrm{~kg}$ de $\mathrm{CO}_{2}$ para cada tonelada de aço produzido na indústria metalúrgica. [2]

Por outro lado, a maior parte das emissões de $\mathrm{CO}_{2}$ na produção e ferro e aço ocorre durante a produção de ferro gusa nos altos-fornos. Isto se deve devido a interação do minério com o carbono presente no coque. A combustão do coque libera CO e $\mathrm{CO}_{2}$, que são gases necessários para a redução do minério de ferro. Contudo, o $\mathrm{CO}_{2}$ é um dos principais gases causadores do efeito estufa. Deste modo, a utilização de agentes redutores menos agressivos ao meio ambiente, como o hidrogênio e o gás natural, são estudados.

Através da Tabela 1, pode-se observar a geração de $\mathrm{CO}_{2}$ baseada em carvão, em diferentes etapas da produção de aço.

Tabela 1: Emissões de $\mathrm{CO}_{2}$ na indústria metalúrgica em diferentes processos [3]

\begin{tabular}{lc}
\hline Processo & $\begin{array}{c}\text { Emissões } \\
\text { (kg CO} / \text { ton de aço } \\
\text { bruto })\end{array}$ \\
\hline Alto-forno & 1.537 \\
\hline Produção de coque & 103 \\
\hline Sinterização & 285 \\
\hline Pelotização & 52 \\
\hline Fabricação de aço & 250 \\
\hline Total & 2.227 \\
\hline
\end{tabular}

Pode-se observar que o a produção de gusa no alto-forno e o processo de sinterização são os principais responsáveis na emissão de $\mathrm{CO}_{2}$. Assim, estudos de redução dos óxidos de ferro que não utilizam/otimizam estas etapas estão sendo cada vez mais estudadas.

Com isso, este trabalho tem por objetivo o estudo dos efeitos da substituição do coque por carvão vegetal durante o processo de sinterização de minérios de ferro na redução por hidrogênio.

\section{MATERIAIS E MÉTODOS}

Neste trabalho, foram produzidos sínteres de minérios de ferro utilizando coque e carvão vegetal como combustível. O coque foi substituído gradativamente em seis bateladas diferentes, assim foram realizadas substituições de coque por carvão vegetal em $0 \%, 8 \%, 16 \%, 25 \%, 50 \%$ e $100 \%$.

No processo tradicional, podem ser feitos ajustes na composição das matérias primas mediante a troca de um combustível. Contudo, a proporção das matérias 
primas no processo de sinterização foram fixadas com o intuito de avaliar a influência da substituição do coque por carvão vegetal no processo de sinterização. Na Figura 1, pode-se observar um esquema do sinterizador utilizado nos ensaios.

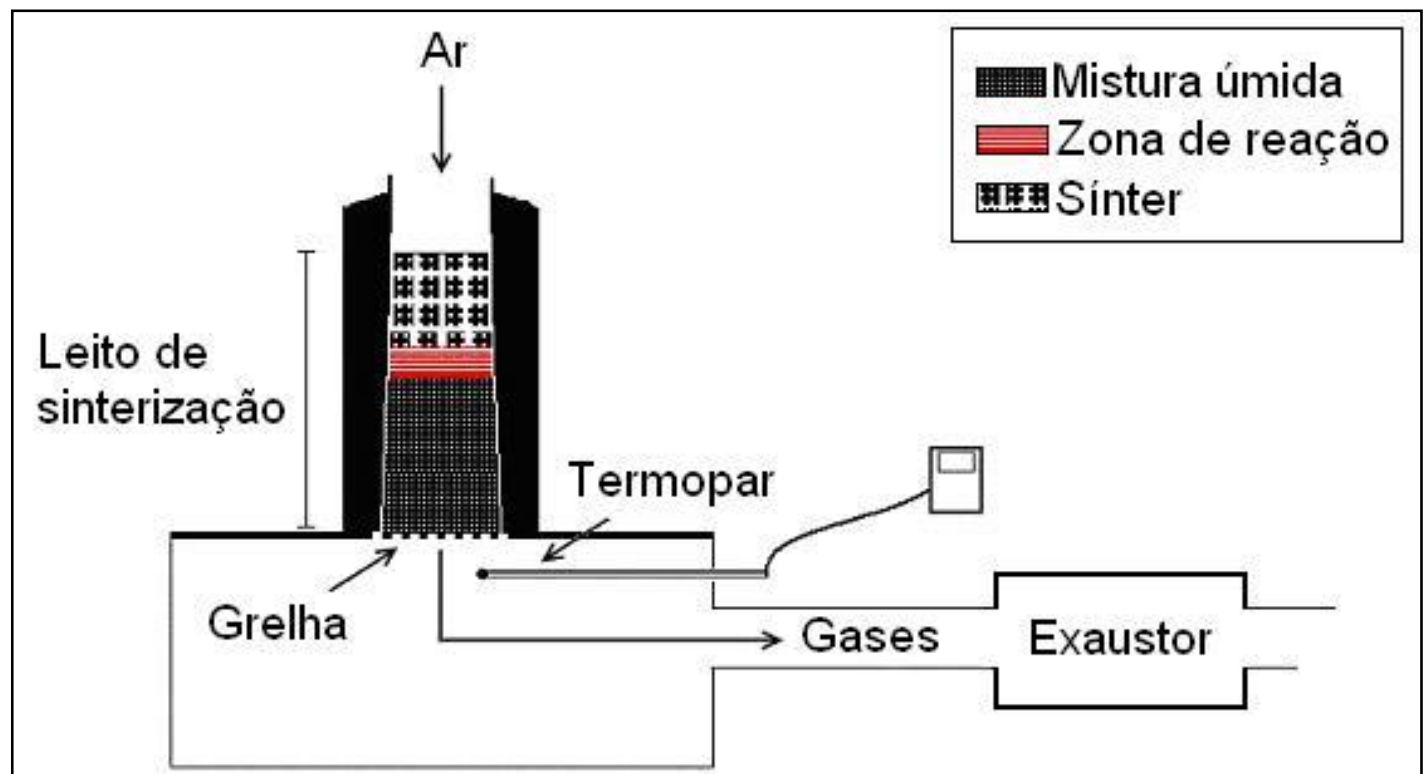

Figura 1: Esquema do aparato experimental utilizado nos ensaios de sinterização.

A produtividade e a permeabilidade dos diferentes ensaios de sinterização foram avaliados, bem como a qualidade do sínter produzido através de teste de tamboreamento.

Os sínteres produzidos com 0\%, 50\% e 100\% de carvão vegetal (como combustível) foram submetidos a ensaios de termogravimetria em termobalança da marca NETZSCH $449 \mathrm{~F} 1$, utilizando uma mistura gasosa de hidrogênio e argônio $\left(10 \% \mathrm{H}_{2}\right.$ e $\left.90 \% \mathrm{Ar}\right)$ como agente redutor.

A porosidade do sínter de minério de ferro está diretamente relacionada com os diferentes índices de qualidade deste material. Uma vez que os poros estão distribuídos no sínter de forma heterogênea, optou-se por realizar ensaios de redução em termobalança somente nas três amostras (100\% carvão vegetal, $50 \%$ carvão vegetal/ $50 \%$ coque e $100 \%$ coque) para não haver sobreposição das curvas.

Foram utilizadas técnicas de microscopia óptica e microscopia eletrônica de varredura para a caracterização dos combustíveis e dos sínteres produzidos.

\section{RESULTADOS E DISCUSSÃO}

Os índices dos ensaios de sinterização podem ser vistos na Tabela 2. Os ensaios foram nomeados como CV(carvão vegetal) e X\% (porcentagem de carvão vegetal utilizado como combustível). 
Tabela 2: Índices de sinterizacão.

\begin{tabular}{cccc}
\hline Sinterização & $\begin{array}{c}\text { Depressão } \\
\text { inicial (mbar) }\end{array}$ & $\begin{array}{c}\text { Depressão } \\
\text { final (mbar) }\end{array}$ & $\begin{array}{c}\mathbf{T}_{\text {máx. saida de gases }} \\
\left({ }^{\circ} \mathbf{C}\right)\end{array}$ \\
\hline Cvzero\% & 87 & 59 & 659,3 \\
\hline Cv8,0\% & 89 & 58 & 703,9 \\
\hline Cv16\% & 89 & 57 & 765,8 \\
\hline Cv25\% & 90 & 56 & 387,7 \\
\hline Cv50\% & 92 & 60 & 388,8 \\
\hline Cv100\% & 94 & 67 & 442,2 \\
\hline
\end{tabular}

Um dos parâmetros que pode determinar a permeabilidade de mistura durante a sinterização é a depressão dos gases. A depressão é inversamente proporcional a permeabilidade da mistura de sinterização. Isto ocorre devido a pressão negativa dos gases estar relacionada com a dificuldade com que os gases possuem para atravessar o leito de sinterização $[4,5]$. Deste modo, a substituição de coque por carvão vegetal diminuiu a permeabilidade da mistura de sinterização. Também é possível observar que houve maiores temperaturas de sinterização para as amostras com maior teor de coque na mistura, indicados pelos valores de temperatura de saída de gases durante a sinterização.

Nas Figuras 2 e 3, pode-se observar as diferentes estururas morfológicas do coque e do carvão vegetal utilizados neste trabalho.

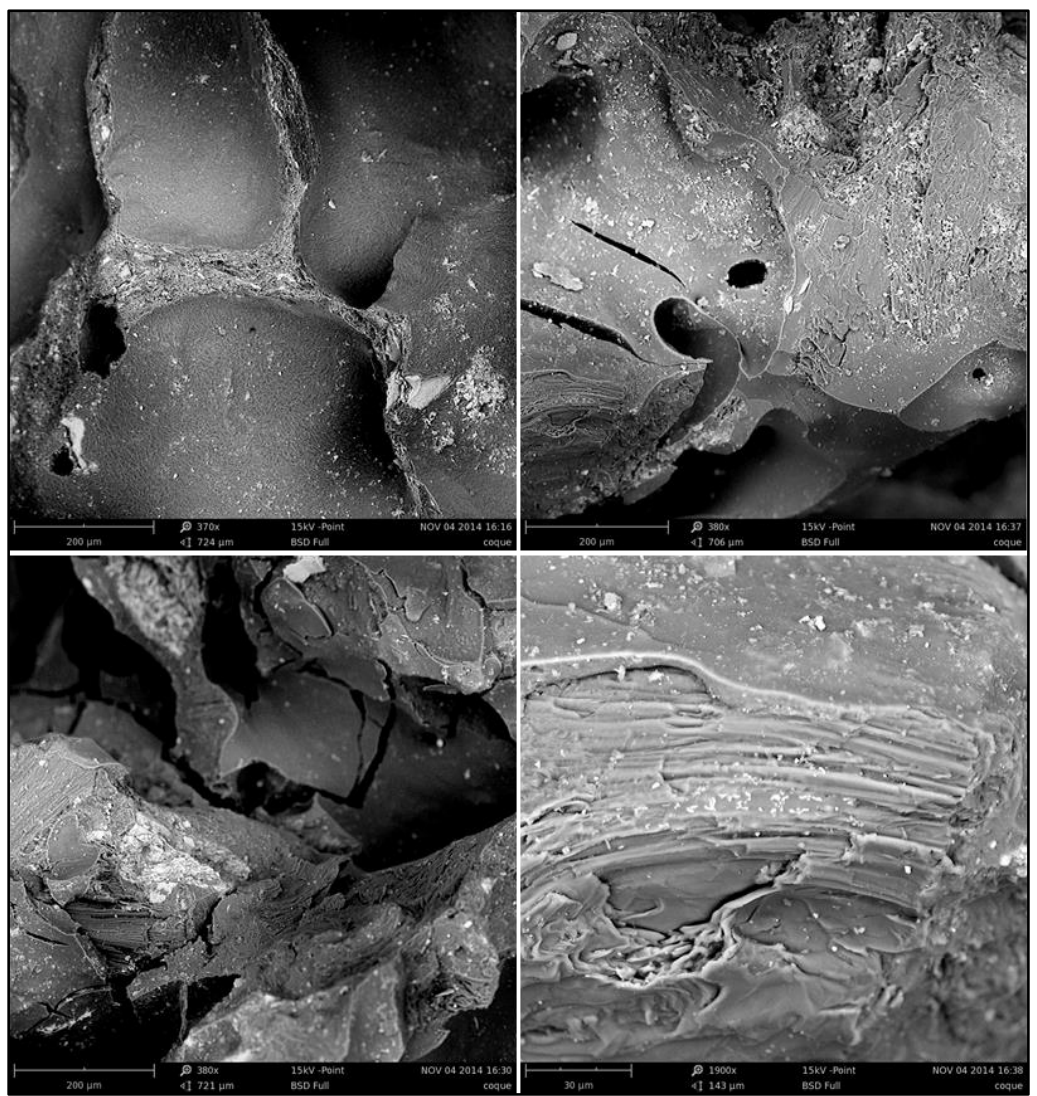

Figura 2: Imagem de elétrons retroespalhados obtidas da amostra de coque. 


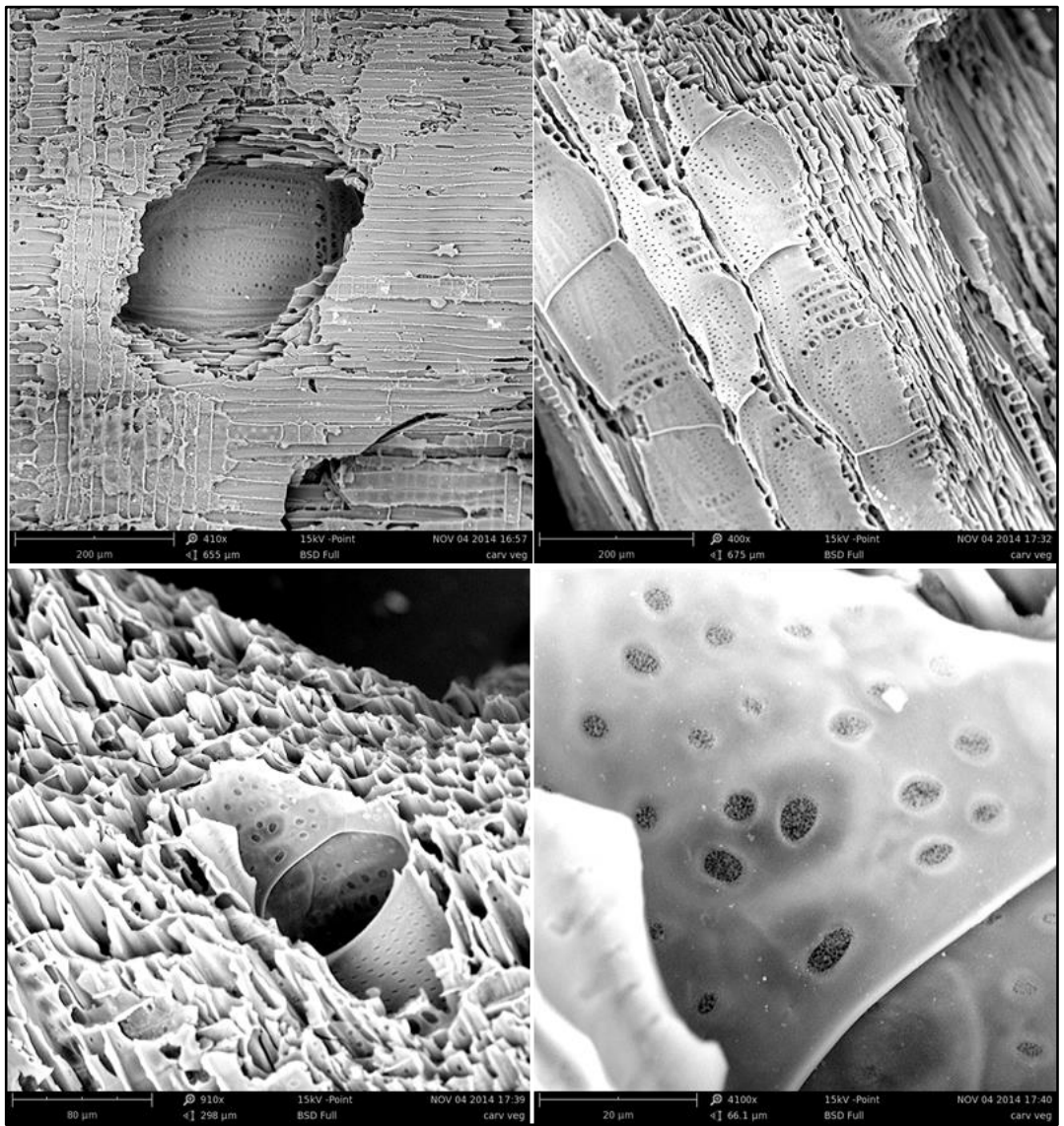

Figura 3: Imagem de elétrons retroespalhados obtidas da amostra de carvão vegetal.

O carvão vegetal possui maior porosidade que o coque. Por outro lado, o coque é mais denso e resistente (resistência mecânica do coque: $170 \mathrm{kgf} / \mathrm{cm}^{2}$ e resistência mecânica do carvão vegetal: $70 \mathrm{kgf} / \mathrm{cm}^{2}$ ). Levando em consideração estes índices, pode-se inferir que a diminiuição da permeabilidade da mistura causada pela substituição do coque pelo carvão vegetal, pode ter ocorrido pela geração de finos durante a etapa de micropelotização. A micropelotização é uma etapa de préaglomeração dos finos de minérios de ferro, realizada com a mistura fria, antes da sinterização propriamente dita.[6]

No processo de sinterização de minérios de ferro, parâmetros de processo de sinterização (composição química das matérias primas, permeabilidade da mistura, basicidade, temperatura de sinterização e porosidade do sínter) estão relacionados com os índices de qualidade do sínter (redutibilidade, resistência mecânica e índice de degradação sob redução). Além disso, estes fatores estão relacionados entre si. Um exemplo disto é a porosidade do sínter, este aumenta consideravelmente a redutibilidade do sínter, contudo pode diminuir a resistência mecânica do mesmo. Desta forma, por mais que existam testes que auxiliam a determinar os melhores parâmetros para serem utilizados na sinterização, a heterogeneidade do sínter, tanto em termos de composição das fases quanto a distribuição dos poros, consiste no maior desafio para o estudo deste processo.

A heterogeneidade das amostras de sínter foi levada em consideração no ensaio de redução por hidrogênio. Desta forma, optou-se por estudar somente as amostras de sínter produzidas com 100\% de cada combustível (CVzero\% e CV100\%) e da amostra com metade de ambos os combustíveis (CV50\%).

Na Figura 4, é possível observar os resultados dos testes de redução por hidrogênio em termobalança. 


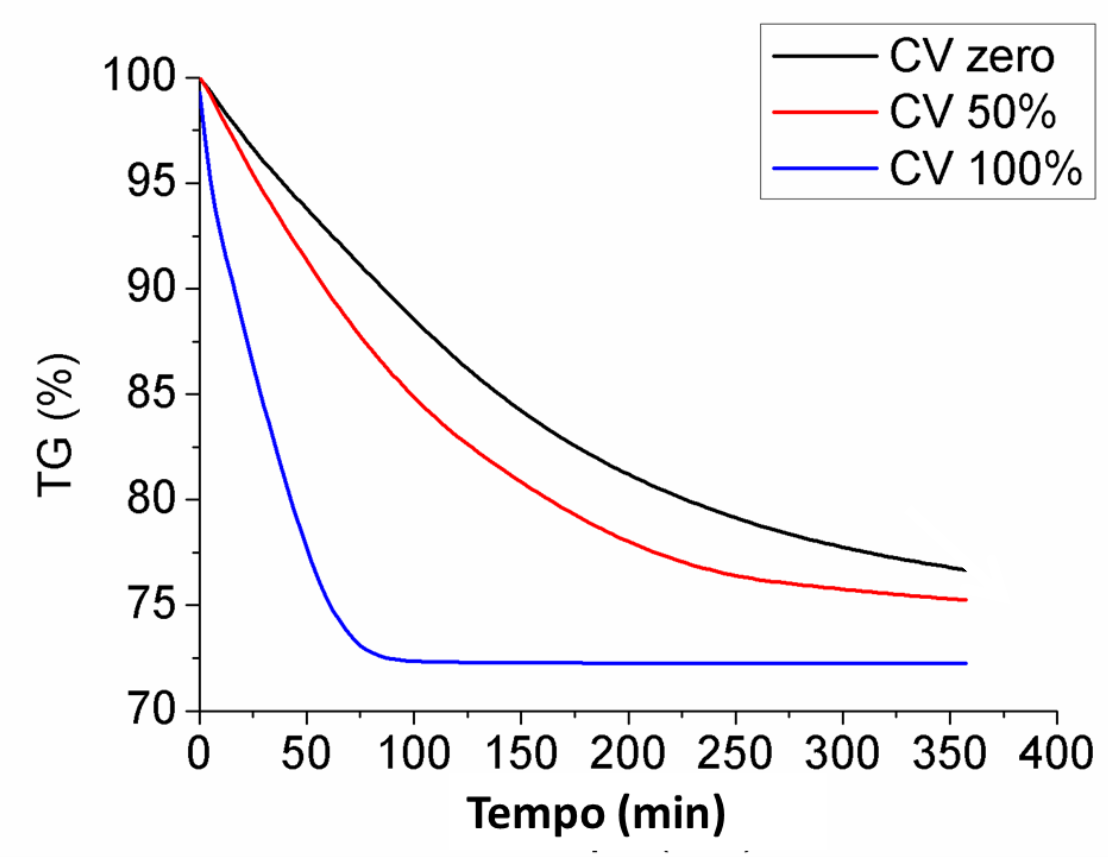

Figura 4: Perda de massa em função do tempo das amostras CVzero, CV50\% e CV100\%. Temperatura: $1000^{\circ} \mathrm{C}$, tempo: 6horas, atmosfera: Argônio- $10 \% \mathrm{H}_{2}$.

Os sínteres produzidos com maiores teores de carvão vegetal apresentaram maiores índices de redução.

$\mathrm{Na}$ amostra com $100 \%$ de carvão vegetal, observa-se que a partir de aproximadamente $80 \mathrm{~min}$ a perda de massa se manteve constante, indicando que 0 sínter atingiu redução completa. Neste caso, o total da perda de massa foi de $27,75 \%$. As amostras com ambos os combustíveis (50\% coque e $50 \%$ carvão vegetal) e com coque (CVzero\%) não reduziram totalmente durante as 6 horas de ensaio. O sínter CV50\% perdeu $24,76 \%$ de massa e CVzero\% perdeu $23,32 \%$. Nestes dois casos, a taxa de redução foi mais lenta, não completando a redução durante o período analisado.

Nos sínteres produzidos com carvão vegetal, notou-se maior quantidade de hematita primária (minério não fundido durante a sinterização). A hematita primária possui características desejáveis no processo de redução (maior porosidade e redutibilidade se comprada com as outras fases presentes no sínter). Devido a isto, deixou-se de produzir sínter completamente fundido nos últimos anos. [7]

$\mathrm{Na}$ Figura 5, pode-se observar imagens de microscopia óptica dos sínteres produzidos. 

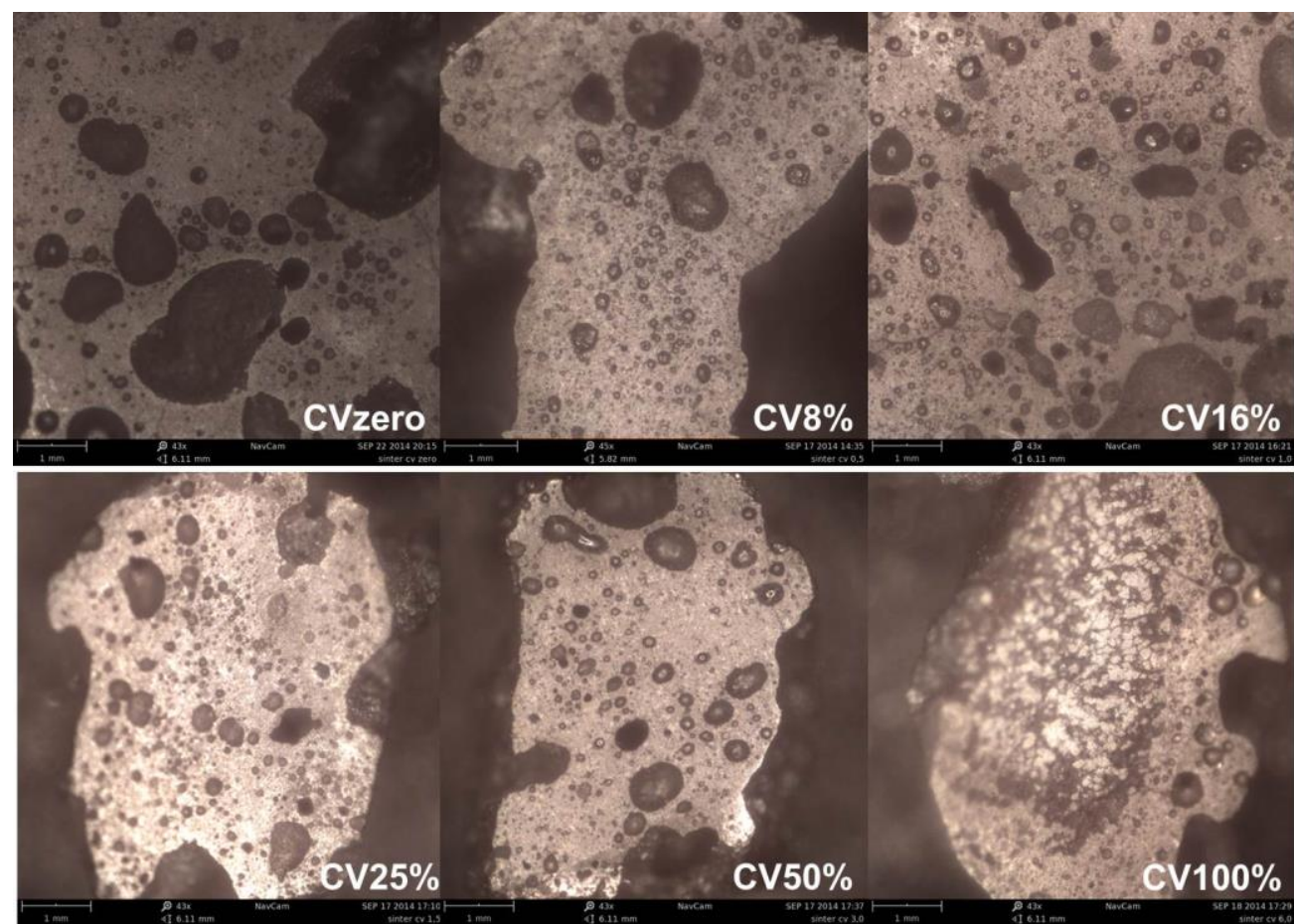

Figura 5: Imagem de microscopia óptica dos sínteres produzidos Hematita primária $(\mathrm{Hp})$

Nota-se a presença de hematita primária no sínter com $100 \%$ de carvão vegetal. Assim, possivelmente a hematita primária favoreceu as reações sólido-gás durante 0 processo de redução, promovendo maior redutibilidade do sínter com maiores quantidades de carvão vegetal.

\section{CONCLUSÃo}

Para misturas com a mesma proporção das matérias primas, a subsitituição de coque por carvão vegetal diminuiu as permeabilidades e temperaturas no interior do leito de sinterização. Consequentementente, houve maiores quantidades de hematita primária nas sinterizações com maiores teores de carvão vegetal.

Os sínteres produzidos utilizando carvão vegetal na mistura de sinterização, obtiveram melhores índices de redutibilidade. Uma vez que a hematita primária possui maior porosidade intrínseca, esta favorece as reações entre o minério e o gás redutor, facilitando o processo de redução, aumentando a cinética de reação e redutibilidade do aglomerado.

\section{Agradecimentos}

Os autores agradecem ao CNPq pelo apoio durante a pesquisa.

\section{REFERÊNCIAS}

1 WORLDSTEEL ASSOCIATION. Steel's contribution to a low carbon future.

Disponível em < http://www.worldsteel.org/publications/bookshop/productdetails. Steel-s-Contribution-to-a-Low-Carbon-Future-2013 PRODUCT Steels-Contribution-to-a-Low-Carbon-Future .html > Acesso em 12/10/2014.

2 LOVEL, R. et al. Iron ore sintering with charcoal. Mineral Processing and Extractive Metallurgy. Vol. 116. n.2. p. 85 - 92, 2007. 
3 ORTH, A.; ANASTASIJEVIC, N.; EICHBERGER, H. Low $\mathrm{CO}_{2}$ emission technologies for iron and steelmaking as well as titania slag production. Minerals Engineering. n.20, p.854-861, 2007. Disponivel em < http://www.sciencedirect.com/science> Acesso em 05/03/2010.

4 HONORATO, E. P. Adequação granulométrica das matérias-primas e do sistema de segregação contínua (I.S.F), para melhorias na produtividade e qualidade do sínter para os altos-fornos. 2005. 114p. Dissertação (Mestrado). Engenharia Metalúrgica e de Minas da Universidade Federal de Minas Gerais, Belo Horizonte - MG, 2005. p. 6, 7, 9-11, 15, 16, 18, 21, 22.

5 TAKANO, C. Estudo da influência de alguns combustíveis na sinterização de minério de ferro. 1970. 101p. Tese (Doutorado) - Escola Politécnica, Universidade de São Paulo, São Paulo, 1970. p.13, 14, 29-33.

6 ARAÚJO, T.P; VIEIRA, J.S.C; ARAÚJO, J.A; ANJOS, D.F Análise imediata do carvão vegetal produzido na região do alto-turi/ MA e sua possível aplicação em alto-forno para a produção de ferro-gusa, 2010. Acessado em 05 abr. 2014

7 ISHIKAWA, Y et al. Recent progress in the sintering technology - high reducibility and improvement of fuel consumption. Ironmaking Conference Proceedings, AIME, v. 41, p. 80-89, 1982. 